\title{
Analysis of a proposed connection for the two-winding single-phase self-excited induction generator operating at constant voltage and frequency
}

\author{
H. H. Hanafy ${ }^{1}$, Heba. M. Soufi ${ }^{2}$ Amr A. Saleh ${ }^{2 *}$ (1) and Magdy B. Eteiba ${ }^{2}$
}

*Correspondence:

aae00@fayoum.edu.eg

${ }^{2}$ Electrical Engineering

Department, Faculty

of Engineering, Fayoum

University, Fayoum 63514,

Egypt

Full list of author information is available at the end of the article

\begin{abstract}
This paper introduces the steady-state and dynamic behaviors of a proposed connection for the two-winding single-phase self-excited induction generator (TWSPSEIG) equipped with an excitation capacitor and a compensation capacitor for operation at constant load voltage and frequency irrespective of the no-load or different load conditions. The performance equations at steady-state conditions are attained by applying loop impedance method via the exact equivalent circuit models of the TWSPSEIG based on the double revolving field theory. Keeping the values of the excitation capacitor and the compensation capacitor as unknowns, two second-order equations, for given values of generator parameters, prime mover speed, frequency and load impedance, are derived. These equations are solved using simple iterative method to calculate the optimum values of the two capacitors under the constraints that the load voltage and frequency are constant. The range of capacitor variations for variable load at variable prime mover speed is also calculated. The steady-state results are verified by developing the dynamic model of the proposed connection incorporating its nonlinearity behavior and various no-load and load conditions. The dynamic behavior of the proposed connection proves the capabilities of the proposed configuration and calculation method to maintain both the load voltage and frequency constants. A comparative study between the performances of the proposed connection and the traditional connection of the TWSPSEIG is presented to illustrate the merits of the proposed connection.
\end{abstract}

Keywords: Single-winding single-phase self-excited induction generators (SWSPSEIG), Two-winding single-phase self-excited induction generators (TWSPSEIG)

\section{Introduction}

The single-phase self-excited induction generators (SPSEIG) are the best choice for supplying small and remote loads, where grid extension is not possible. The robust cage rotor construction, low cost, absence of exciter, self-protection against fault and stable operation are the essential advantages of the SPSEIG. The self-excitation of the SPSEIG is similar to that in the three-phase induction generators, as they are unable to generate their air gap magnetic field. So, in the isolated mode, they must be equipped with terminal capacitors, for supplying their air gap magnetic field in the form of reactive power.

(c) The Author(s) 2019. This article is distributed under the terms of the Creative Commons Attribution 4.0 International License (http://creativecommons.org/licenses/by/4.0/), which permits unrestricted use, distribution, and reproduction in any medium, provided you give appropriate credit to the original author(s) and the source, provide a link to the Creative Commons license, and indicate if changes were made. 
The key factor for voltage building up in SPSEIG is the selection of the proper excitation capacitance $[1,2]$. The SPSEIG can be operated in two different classes which are the single-winding SPSEIG (SWSPSEIG) and the two-winding SPSEIG (TWSPSEIG). In the single-winding class, both the excitation capacitor and load are connected in parallel across the main winding $[1,2]$. In the two-winding class, a fixed capacitor is connected across the auxiliary winding for excitation purpose and a compensation capacitor is placed in series or parallel with the load across the main winding [3]. Steady-state analysis of SWSPSEIG is always carried out using the double revolving field theory, while that of TWSPSEIG is always carried out using the double revolving field theory combined with the symmetrical components theory. Then the performance equations of the SPSEIG are obtained using nodal admittance or loop impedance methods applied to the SPSEIG circuits. Two nonlinear higher-order simultaneous equations are constructed manually by equating the real and imaginary parts of the complex impedance or admittance to zero. These equations have the magnetizing reactance and frequency as two unknowns, while their coefficients are functions of the SPSEIG parameters, prime mover speed, load impedance and the capacitors used according to the configuration of the SPSEIG. The two nonlinear higher-order simultaneous equations were then solved by arithmetical techniques such as the Newton-Raphson method [4], Rosenbrock's method of rotating coordinate [5] and Matlab-fsolve [1, 2]. Once the equations are solved, the analysis of the SPSEIG performance becomes straightforward. In [6], the author presented a new approach based on minimizing the impedance equation of the generator to calculate the unknown parameters. The presented approach is easier to implement than other methods of analysis and could be carried out with Matlab software. In [7], the authors developed the mathematical models of SPSEIG using graph theory. Graph theory is used since it results in matrix form and the same models can be used for any load and any combination of unknown parameters of the equivalent circuit. Also, a method using genetic algorithm has been developed. The main disadvantages of the SPSEIG are the poor voltage regulation, lower output power and efficiency due to nonlinearity behavior of the SPSEIG and the backward rotating field. There is wide literature on improving the voltage regulation and output power. To enhance the voltage regulation of the SPSEIG, different capacitor topologies are introduced such as capacitors connected in series, shunt, long shunt, and short shunt connection with load [8]. In [1, 2], the genetic algorithm has been used to obtain the optimum values of the capacitors for different topologies for optimum voltage regulation. It is reported that topologies that contain series capacitor perform better for inductive load, while the shunt capacitor configuration gives good performance at high speeds of prime mover; on the other hand, the single-capacitor configuration is acceptable for resistive load. To enhance power generation and power quality of TWSPSEIG, the authors in [9] presented a leaky minimal disturbance theory-based decoupled voltage and frequency controller. In [10], the author used fuzzy logic and practical approach to calculate the optimal capacitor for the maximum output power of SWSPSEIG. A lot of research has been carried out to maintain the voltage and frequency of the SPSEIG constants under the variations of different operating conditions such as the prime mover speed and load dynamics. The most popular technique to regulate the voltage and frequency is using the electronic load controller. In [11-13], a dummy load is used to compensate the fluctuation of the 
consumer load by controlling the dump load power. Another popular way to control voltage is using thyristor switched capacitor scheme to vary the reactive power supply [11-13]. In [14], the authors used a single-phase microprocessor controlled PWM inverter to regulate the output frequency of TWSPSEIG driven by a variable speed prime mover, while the excitation capacitor group is controlled by the microprocessor to keep the terminal voltage of the generator constant at different operating conditions. In [11-13], the authors proposed a voltage source converter connected to a battery energy storage system at its DC bus. The system is controlled by an intelligent neural networkbased control algorithm to maintain the voltage and frequency constant at all loading conditions. In [15], the authors proposed a combined control system that includes a dummy load and an inferior voltage control system, by adjusting the excitation capacitor connected to the auxiliary winding, to maintain the system voltage and frequency constant of a TWSPSEIG. On the other hand besides the use of a single-phase generator, a three-phase induction machine with a balancing circuit represents a dependable choice. Efforts have been exerted to investigate and improve the balanced operation of a three-phase induction generator in single-phase mode [16, 17]. There are many balancing configurations used in literature. For star-connected generators, some of them used three capacitors such as Fukami connection (three capacitors of which two are identical) and Smith connection (three capacitors with special arrangement of the stator winding), but the others used one capacitor connected across one or two of the three phases while the load is connected across either the other two phases or one phase. In case of delta-connected generators, some of the balancing configurations are Steinmetz connection (two capacitors: one connected across the lagging phase and the other in series with the load, across the reference phase) or $C / 2 C$ connection (' $2 C$ ' capacitance across one phase and ' $C$ ' capacitance across another phase and in parallel with the load) [18]. In [19], an improved low-cost SPSEIG using a three-phase induction machine for constant voltage and frequency operation was proposed. Excitation for such a generator is provided by using a fixed capacitor, connected across one of its phases and the neutral in parallel with the load, and a single-phase inverter along with a photovoltaic module across the other two phases. In [20], a new configuration of single-phase generator using a three-phase induction machine was proposed, in which the windings of the induction machine are separated and two of the windings are excited by two independent excitation sources, while the third winding is connected to a load with a shunt capacitor. The main disadvantage of these configurations is that they require inverters for excitation sources. A microcontroller-based electronic load controller for voltage regulation of a star-connected three-phase self-excited induction generator with three-capacitor configuration, feeding single-phase loads, was presented in [21]. In this paper, the authors propose a new connection for the TWSPSEIG together with an exact computational methodology to size the excitation and compensation capacitances to maintain constant load voltage and frequency.

\section{Method}

The configuration of the proposed new connection is shown in Fig. 1, where an excitation capacitor " $C_{\mathrm{A}}$ " is connected in parallel to the auxiliary winding and then the parallel combination is connected in series to the main winding, and a compensation capacitor 




Fig. 1 The configuration of the proposed connection of TWSPSEIG

" $C_{\mathrm{M}}$ ", which is shunted with the load, is connected across the terminals of the combination of the main and the auxiliary windings. The performance equations at steady-state conditions are obtained by applying loop impedance method through the exact equivalent circuit model of the TWSPSEIG based on the double revolving field theory. Rather than the conventional methods of analysis, to get two nonlinear higher-order equations keeping the magnetizing reactance and the frequency as unknowns, the real and imaginary parts of the complex impedance of the equivalent circuit are rearranged to get two second-order equations keeping the values of the two capacitors " $C_{\mathrm{M}}$ " and " $C_{\mathrm{A}}$ " as unknowns for given values of generator parameters, prime mover speed, output frequency and load impedance. The two second-order equations are solved using a simple iterative method to calculate the optimum values of the two capacitors under the constraints that the load voltage and frequency are constant at the rated values irrespective of the no-load or different-load conditions (different load impedance and power factor). The range of capacitors variations required for maintaining constant load voltage and frequency while supplying variable load at variable prime mover speed is calculated. The steady-state results are confirmed by developing a dynamic model for the proposed connection incorporating various no-load and load conditions and the nonlinearity behavior of the TWSPSEIG. The dynamic behavior at different operating conditions proves the capabilities of the proposed configuration and calculation method to maintain both the load voltage and frequency constants. Also the performance of the new connection was compared with that of the traditional connection to evaluate the new connection and prove its advantages.

\section{The steady-state model of TWSPSEIG}

The equivalent circuit used for the steady-state analysis of the proposed connection for the TWSPSEIG is shown in Fig. 2. The steady-state equivalent circuit is based on the double revolving field theory under the assumptions that neglecting core loss and all the generator parameters are constants and unaffected by saturation except the magnetizing reactances.

\section{No-load model}

At no load, the loop equations for the main and auxiliary currents can be written as: 


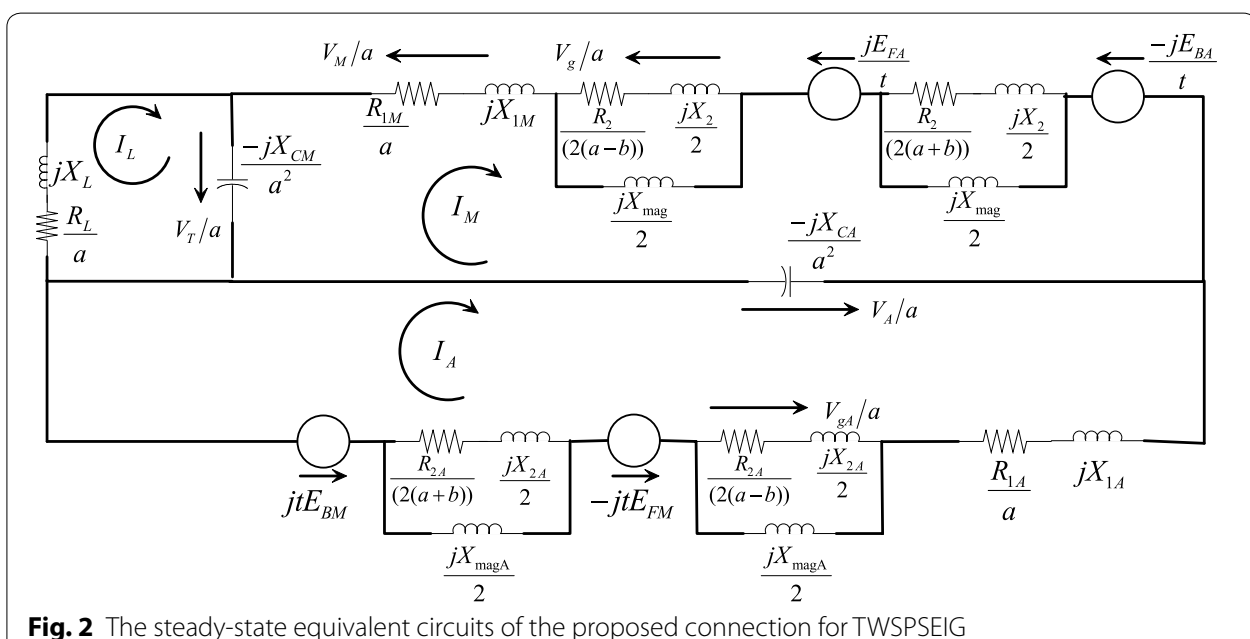

$$
\begin{aligned}
& Z_{0} \cdot I_{\mathrm{S} 0}=0, \\
& I_{\mathrm{S} 0}=\left[\begin{array}{c}
I_{\mathrm{M}} \\
I_{\mathrm{A}}
\end{array}\right], \\
& Z_{0}=\left[\begin{array}{cc}
Z_{\mathrm{M}}-j \frac{\left(X_{\mathrm{CM}}+X_{\mathrm{CA}}\right)}{a^{2}} & \left(j \frac{Z_{\mathrm{FBA}}}{t}+j \frac{X_{\mathrm{CA}}}{a^{2}}\right) \\
\left(j \frac{X_{\mathrm{CA}}}{a^{2}}-j Z_{\mathrm{FBM}} \cdot t\right) & \left(Z_{\mathrm{A}}-j \frac{X_{\mathrm{CA}}}{a^{2}}\right)
\end{array}\right] .
\end{aligned}
$$

Since for steady state $I_{\mathrm{S} 0} \neq 0$, then $\left|Z_{\mathrm{o}}\right|=0$ (i.e., $Z_{\mathrm{o}}$ must be singular matrix). This means that the real and imaginary parts of the determinant of " $Z_{0}$ " must be separately zero; this can be simplified to the following equations, where the imaginary part is as in (4) and the real part is as in (5):

$$
\begin{aligned}
& Z_{1 \mathrm{M}}=\frac{R_{1 \mathrm{M}}}{a}+j X_{1 \mathrm{M}}, \quad Z_{1 \mathrm{~A}}=\frac{R_{1 \mathrm{~A}}}{a}+j X_{1 \mathrm{~A}}, \\
& Z_{\mathrm{FM}}=\frac{\left[\frac{R_{2}}{[2(a-b)]}+j \frac{X_{2}}{2}\right] \cdot\left(j \frac{X_{\mathrm{mag}}}{2}\right)}{\frac{R_{2}}{[2(a-b)]}+j \frac{X_{2}}{2}+j \frac{X_{\mathrm{mag}}}{2}}, \quad Z_{\mathrm{BM}}=\frac{\left[\frac{R_{2}}{[2(a+b)]}+j \frac{X_{2}}{2}\right] \cdot\left(j \frac{X_{\mathrm{mag}}}{2}\right)}{\frac{R_{2}}{[2(a+b)]}+j \frac{X_{2}}{2}+j \frac{X_{\mathrm{mag}}}{2}}, \\
& Z_{\mathrm{FA}}=\frac{\left[\frac{R_{2 \mathrm{~A}}}{[2(a-b)]}+j \frac{X_{2 \mathrm{~A}}}{2}\right] \cdot\left(j \frac{X_{\mathrm{magA}}}{2}\right)}{\frac{R_{2 \mathrm{~A}}}{[2(a-b)]}+j \frac{X_{2 \mathrm{~A}}}{2}+j \frac{X_{\mathrm{magA}}}{2}}, \quad Z_{\mathrm{BA}}=\frac{\left[\frac{R_{2 \mathrm{~A}}}{[2(a+b)]}+j \frac{X_{2 \mathrm{~A}}}{2}\right] \cdot\left(j \frac{X_{\mathrm{magA}}}{2}\right)}{\frac{R_{2 \mathrm{~A}}}{[2(a+b)]}+j \frac{X_{2 \mathrm{~A}}}{2}+j \frac{X_{\mathrm{magA}}}{2}}, \\
& Z_{\mathrm{M}}=Z_{1 \mathrm{M}}+Z_{\mathrm{FM}}+Z_{\mathrm{BM}}, \quad Z_{\mathrm{A}}=Z_{1 \mathrm{~A}}+Z_{\mathrm{FA}}+Z_{\mathrm{BA}}, \\
& Z_{\mathrm{FBM}}=Z_{\mathrm{FM}}-Z_{\mathrm{BM}}, \quad Z_{\mathrm{FBA}}=Z_{\mathrm{FA}}-Z_{\mathrm{BA}} \text {, } \\
& X_{\mathrm{CM}}=\frac{a^{2}}{R_{\mathrm{A}}} *\left(A+B * X_{\mathrm{CA}}\right) \text {, }
\end{aligned}
$$




$$
\begin{aligned}
& \mathrm{AA} * X_{\mathrm{CA}}^{2}+\mathrm{BB} * X_{\mathrm{CA}}+\mathrm{CC}=0, \\
& A=X_{\mathrm{MA}}-X_{\mathrm{FBMA}}, \quad B=\frac{1}{a^{2}} *\left(\frac{X_{\mathrm{FBA}}}{t}-t * X_{\mathrm{FBM}}-R_{\mathrm{M}}-R_{\mathrm{A}}\right), \\
& C=R_{\mathrm{MA}}-R_{\mathrm{FBMA}}, \quad D=\frac{1}{a^{2}} *\left(\frac{R_{\mathrm{FBA}}}{t}-t * R_{\mathrm{FBM}}+X_{\mathrm{M}}+X_{\mathrm{A}}\right) \\
& \mathrm{AA}=\frac{B}{a^{2} * R_{\mathrm{A}}}, \quad \mathrm{BB}=\frac{A}{a^{2} * R_{\mathrm{A}}}-\frac{B * X_{\mathrm{A}}}{R_{\mathrm{A}}}-D, \quad \mathrm{CC}=-\frac{A * X_{\mathrm{A}}}{R_{\mathrm{A}}}-C, \\
& Z_{\mathrm{FBMA}}=Z_{\mathrm{FBM}} * Z_{\mathrm{FBA}}=R_{\mathrm{FBMA}}+j X_{\mathrm{FBMA}}, \quad Z_{\mathrm{MA}}=Z_{\mathrm{M}} * Z_{\mathrm{A}}=R_{\mathrm{MA}}+j X_{\mathrm{MA}} .
\end{aligned}
$$

The saturation portions of the magnetizing reactance of the main and the auxiliary against the air gap voltage can be piecewise linearized and expressed arithmetically in the form:

$$
\begin{aligned}
& X_{\mathrm{mag}}=K_{1}-K_{2} *\left(\frac{V_{\mathrm{g}}}{a}\right), \\
& X_{\mathrm{magA}}=K_{3}-K_{4} *\left(\frac{V_{\mathrm{gA}}}{a}\right),
\end{aligned}
$$

where $K_{1}, K_{2}, K_{3}$ and $K_{4}$ are constants. Based on the analytical technique explained above, the necessary set values of the p.u. speed " $b$ ", the auxiliary capacitor " $C_{\mathrm{A}}$ " and the main capacitor " $C_{\mathrm{M}}$ ", respectively, to insure self-excitation at the desired values of the no-load terminal voltage " $V_{\mathrm{T}}$ " and the p.u. frequency " $a$ ", could be computed as shown in the flowchart of Fig. 3.

\section{Inductive load model}

In this section, a direct and simple technique, to calculate the necessary values of the main and auxiliary capacitors for inductive load conditions is developed to attain the desired values of terminal voltage and frequency. The loop equations for the currents $\left(I_{\mathrm{M}}, I_{\mathrm{A}}\right.$ and $\left.I_{\mathrm{L}}\right)$ are given as:

$$
\begin{aligned}
& Z \cdot I_{\mathrm{S}}=0, \\
& I_{\mathrm{S}}=\left[\begin{array}{c}
I_{\mathrm{M}} \\
I_{\mathrm{A}} \\
I_{\mathrm{L}}
\end{array}\right], \\
& Z=\left[\begin{array}{ccc}
Z_{\mathrm{M}}-j \frac{\left(X_{\mathrm{CM}}+X_{\mathrm{CA}}\right)}{a^{2}} & \left(j \frac{Z_{\mathrm{FBA}}}{t}+j \frac{X_{\mathrm{CA}}}{a^{2}}\right) & j \frac{X_{\mathrm{CM}}}{a^{2}} \\
\left(j \frac{X_{\mathrm{CA}}}{a^{2}}-j Z_{\mathrm{FBM}} \cdot t\right) & \left(Z_{\mathrm{A}}-j \frac{X_{\mathrm{CA}}}{a^{2}}\right) & 0 \\
Z_{\mathrm{L}} & j \frac{X_{\mathrm{CM}}}{a^{2}} & \left(Z_{\mathrm{L}}-j \frac{X_{\mathrm{CM}}}{a^{2}}\right)
\end{array}\right], \\
& R_{\mathrm{L}}+j X_{\mathrm{L}} .
\end{aligned}
$$




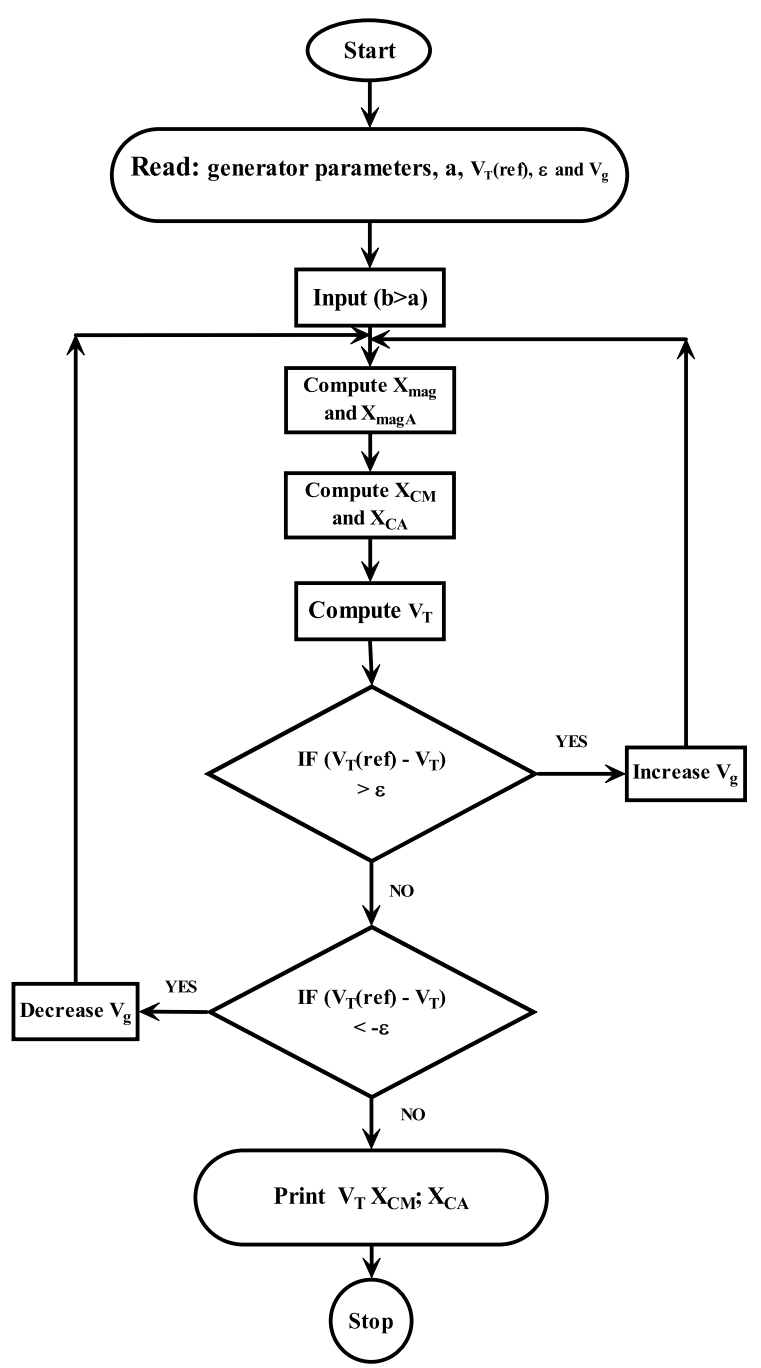

Fig. 3 The flowchart of no-load computer algorithm

From (9) since under steady state, $I_{\mathrm{s}} \neq 0$, then $|Z|=0$ (i.e., $Z_{\mathrm{o}}$ must be singular matrix). This means that the real and imaginary parts of the determinant of " $Z$ " must be separately zero; this could be rearranged to the following two nonlinear equations where the imaginary part is as in (11) and the real part is as in (12):

$$
\begin{gathered}
X_{\mathrm{CA}}=\frac{X_{\mathrm{H} 1}+R_{\mathrm{H} 2} \cdot \frac{X_{\mathrm{CM}}}{a^{2}}}{A_{2} \cdot\left(\frac{X_{\mathrm{CM}}}{a^{4}}\right)-A_{1}}, \\
\mathrm{AA} 1 * X_{\mathrm{CM}}^{2}+\mathrm{BB} 1 * X_{\mathrm{CM}}+\mathrm{CC} 1=0,
\end{gathered}
$$

where:

$$
\mathrm{AA} 1=\frac{A_{4} * R_{\mathrm{H} 2}-A_{2} * X_{\mathrm{H} 2}}{a^{6}}, \quad \mathrm{BB} 1=\frac{A_{2} * R_{\mathrm{H} 1}}{a^{4}}+\frac{A_{1} * X_{\mathrm{H} 2}}{a^{2}}+\frac{A_{3} * R_{\mathrm{H} 2}}{a^{4}}+\frac{A_{4} * X_{\mathrm{H} 1}}{a^{4}},
$$




$$
\begin{aligned}
& \mathrm{CC} 1=\frac{A_{3} * X_{\mathrm{H} 1}}{a^{2}}-A_{1} * R_{\mathrm{H} 1}, \\
& A_{1}=X_{\mathrm{H} 3}-R_{\mathrm{H} 4}, \quad A_{2}=X_{\mathrm{H} 5}+R_{\mathrm{H} 6}, \\
& A_{3}=R_{\mathrm{H} 3}+X_{\mathrm{H} 4}, \quad A_{4}=X_{\mathrm{H} 6}-R_{\mathrm{H} 5}, \\
& Z_{\mathrm{H} 1}=Z_{\mathrm{MAL}}-Z_{\mathrm{FBMAL}}=R_{\mathrm{H} 1}+j X_{\mathrm{H} 1}, \quad Z_{\mathrm{H} 2}=Z_{\mathrm{FBMA}}-Z_{\mathrm{MA}}-Z_{\mathrm{AL}}=R_{\mathrm{H} 2}+j X_{\mathrm{H} 2}, \\
& Z_{\mathrm{H} 3}=\frac{Z_{\mathrm{FBAL}}}{t}-Z_{\mathrm{FBML}} * t=R_{\mathrm{H} 3}+j X_{\mathrm{H} 3}, \quad Z_{\mathrm{H} 4}=Z_{\mathrm{ML}}+Z_{\mathrm{AL}}=R_{\mathrm{H} 4}+j X_{H 4}, \\
& Z_{\mathrm{H} 5}=Z_{\mathrm{M}}+Z_{\mathrm{A}}+Z_{\mathrm{L}}=R_{\mathrm{H} 5}+j X_{\mathrm{H} 5}, \quad Z_{\mathrm{H} 6}=\frac{Z_{\mathrm{FBA}}}{t}-Z_{\mathrm{FBM}} * t=R_{\mathrm{H} 6}+j X_{\mathrm{H} 6}, \\
& Z_{\mathrm{FBMAL}}=Z_{\mathrm{FBM}} * Z_{\mathrm{FBA}} * Z_{\mathrm{L}}=R_{\mathrm{FBMAL}}+j X_{\mathrm{FBMAL}}, \quad Z_{\mathrm{FBML}}=Z_{\mathrm{FBM}} * Z_{\mathrm{L}}=R_{\mathrm{FBML}}+j X_{\mathrm{FBML}}, \\
& Z_{\mathrm{FBAL}}=Z_{\mathrm{FBA}} * Z_{\mathrm{L}}=R_{\mathrm{FBAL}}+j X_{\mathrm{FBAL}}, \quad Z_{\mathrm{MAL}}=Z_{\mathrm{M}} * Z_{\mathrm{A}} * Z_{\mathrm{L}}=R_{\mathrm{MAL}}+j X_{\mathrm{MAL}}, \\
& Z_{\mathrm{ML}}=Z_{\mathrm{M}} * Z_{\mathrm{L}}=R_{\mathrm{ML}}+j X_{\mathrm{ML}}, \quad Z_{\mathrm{AL}}=Z_{\mathrm{A}} * Z_{\mathrm{L}}=R_{\mathrm{AL}}+j X_{\mathrm{AL}} .
\end{aligned}
$$

Based on the analytical technique explained above, the necessary set values of the p.u. speed " $b$ ", the auxiliary capacitor " $C_{\mathrm{A}}$ " and the main capacitor " $C_{\mathrm{M}}$ " respectively, to attain the desired values of the load voltage " $V_{\mathrm{T}}$ " and the operating p.u. frequency $(a)$, at generally load impedance $\left(Z_{L}\right)$ could be computed as shown in the flowchart of Fig. 4.

\section{Dynamic model of TWSPSEIG}

Generally, the induction machine models are developed using simplified model in q-d reference frame attached to stator, rotor or synchronous rotating reference. In this work, a $\mathrm{q}$ - $\mathrm{d}$ reference frame attached to the stator as shown in Fig. 1 is used to develop the dynamic model of the proposed connection of the TWSPSEIG. The voltage differential equations in the $\mathrm{q}-\mathrm{d}$ reference frame can be represented as in (13).

$$
\left[\begin{array}{c}
V_{\mathrm{qs}} \\
V_{\mathrm{ds}} \\
V_{\mathrm{qr}} \\
V_{\mathrm{dr}}
\end{array}\right]=\left[\begin{array}{cccc}
R_{1 \mathrm{M}}+p L_{1 \mathrm{M}} & 0 & p L_{\mathrm{mag}} & 0 \\
0 & R_{1 \mathrm{~A}}+p L_{1 \mathrm{~A}} & 0 & p L_{\mathrm{magA}} \\
p L_{\mathrm{mag}} & \frac{-\omega_{\mathrm{r}} L_{\mathrm{magA}}}{t} & R_{2}+p L_{2} & \frac{-\omega_{\mathrm{r}} L_{2 \mathrm{~A}}}{t} \\
\omega_{\mathrm{r}} L_{\mathrm{mag}} \cdot t & p L_{\mathrm{magA}} & \omega_{\mathrm{r}} L_{2} \cdot t & R_{2 \mathrm{~A}}+p L_{2 \mathrm{~A}}
\end{array}\right] \cdot\left[\begin{array}{c}
I_{\mathrm{qs}} \\
I_{\mathrm{ds}} \\
I_{\mathrm{qr}} \\
I_{\mathrm{dr}}
\end{array}\right]
$$

At no-load condition, the main and the auxiliary winding currents and the excitation capacitor current are given in (14), the magnetization current components in the quadrature and direct axes, and the magnitude of the magnetizing current are given in (15).

$$
\begin{aligned}
& I_{\mathrm{qs}}=I_{\mathrm{M}}=I_{\mathrm{CM}}, \quad I_{\mathrm{ds}}=I_{\mathrm{A}}, \quad I_{\mathrm{CA}}=I_{\mathrm{qs}}-I_{\mathrm{ds}} \\
& I_{\mathrm{magq}}=I_{\mathrm{qs}}+I_{\mathrm{qr}}, \quad I_{\mathrm{magd}}=I_{\mathrm{ds}}+I_{\mathrm{dr}}, \quad I_{\mathrm{mag}}=\frac{\sqrt{I_{\mathrm{magq}+}^{2} I_{\mathrm{magd}}^{2}}}{\sqrt{2}} .
\end{aligned}
$$

The generator terminal voltages as a function of the generator currents at no-load condition are given by: 


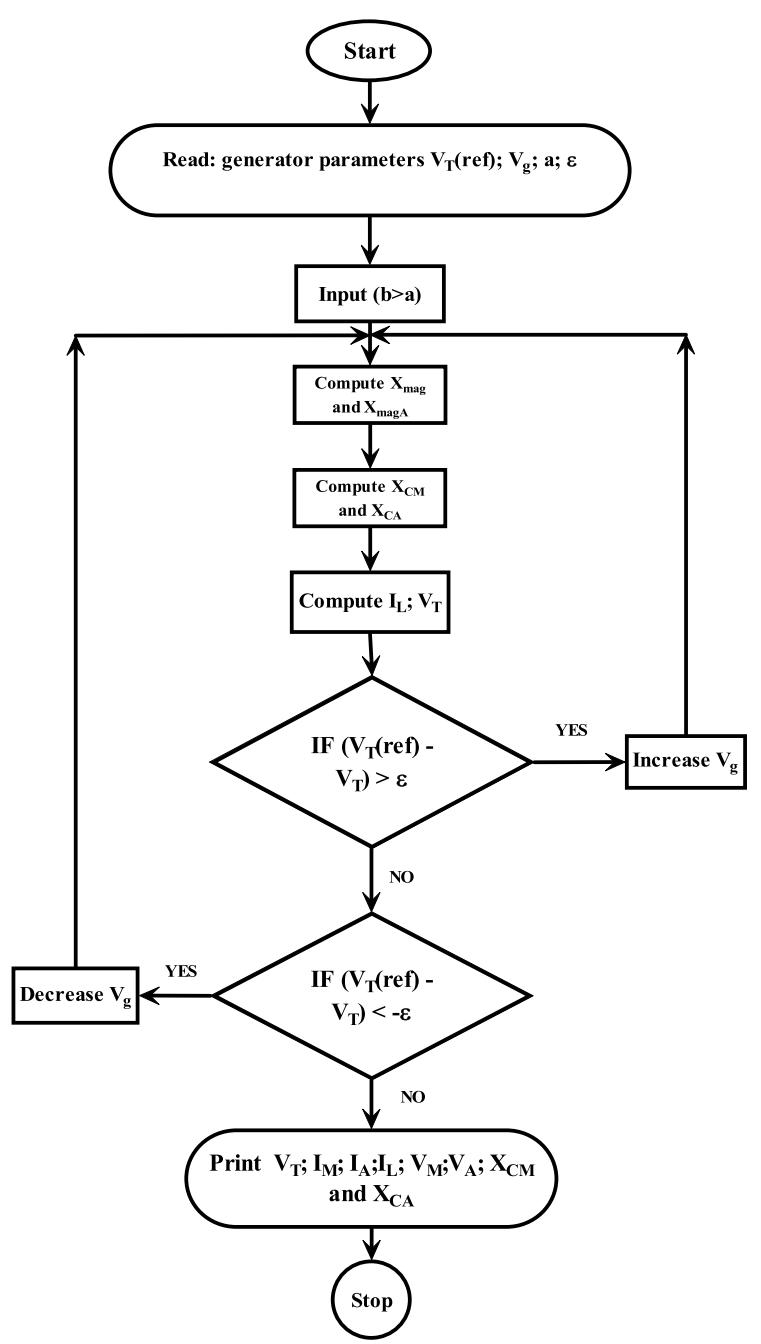

Fig. 4 The flowchart of load computer algorithm

$$
p V_{\mathrm{T}}=\frac{I_{\mathrm{qs}}}{C_{\mathrm{M}}}, \quad p V_{\mathrm{ds}}=\frac{\left(I_{\mathrm{qs}}-I_{\mathrm{ds}}\right)}{C_{\mathrm{A}}}, \quad V_{\mathrm{qs}}=-V_{\mathrm{ds}}-V_{\mathrm{T}}
$$

At load condition, the TWSPSEIG is loaded with a load connected to the generator terminals across the main winding (compensation) capacitor " $C_{\mathrm{M}}$ ". To develop the generator dynamic model considering the load, the q-d components of the stator currents have to be computed as in (17).

$$
I_{\mathrm{qs}}=I_{\mathrm{CM}}+I_{\mathrm{Lq}}, \quad I_{\mathrm{ds}}=I_{\mathrm{A}}, \quad I_{\mathrm{CA}}=I_{\mathrm{qs}}-I_{\mathrm{ds}} .
$$

The generator terminal voltages $\left(V_{\mathrm{qs}}, V_{\mathrm{ds}}\right)$ as a function of the generator currents $\left(I_{\mathrm{qs}}\right.$, $\left.I_{\mathrm{ds}}\right)$ and the load current $\left(I_{\mathrm{Lq}}\right)$ at load condition are given by:

$$
\begin{gathered}
p V_{\mathrm{ds}}=\frac{\left(I_{\mathrm{qs}}-I_{\mathrm{ds}}\right)}{C_{\mathrm{A}}}, \quad p V_{\mathrm{T}}=\frac{\left(I_{\mathrm{qs}}-I_{\mathrm{Lq}}\right)}{C_{\mathrm{M}}}, \\
p I_{\mathrm{Lq}}=\frac{\left(V_{\mathrm{T}}-R_{\mathrm{L}} \cdot I_{\mathrm{Lq}}\right)}{L_{\mathrm{L}}}, \quad V_{\mathrm{qs}}=-V_{\mathrm{T}}-V_{\mathrm{ds}} .
\end{gathered}
$$


Table 1 Equivalent circuit parameters of the TWSPSEIG

\begin{tabular}{lllllllll}
\hline $\boldsymbol{R}_{\mathbf{1 M}}$ & $\boldsymbol{R}_{\mathbf{1 A}}$ & $\boldsymbol{R}_{\mathbf{2}}$ & $\boldsymbol{R}_{\mathbf{2 A}}$ & $\boldsymbol{X}_{\mathbf{2}}$ & $\boldsymbol{X}_{\mathbf{2 A}}$ & $\boldsymbol{X}_{\mathbf{1 M}}$ & $\boldsymbol{X}_{\mathbf{1 A}}$ & $\boldsymbol{t}$ \\
\hline $3.41 \Omega$ & $11.22 \Omega$ & $4.37 \Omega$ & $8.01 \Omega$ & $3.99 \Omega$ & $6.433 \Omega$ & $3.99 \Omega$ & $6.433 \Omega$ & 1.4 \\
\hline
\end{tabular}

\section{Results and discussion}

The performance characteristics of $0.75 \mathrm{~kW}, 230 \mathrm{~V}, 6 \mathrm{~A}$, 4-poles and $50 \mathrm{~Hz}$ single-phase induction generator are carried out via the proposed technique. Table 1 gives the parameters of the generator. The magnetization characteristics of the TWSPSEIG are shown in Fig. 5. Results for steady-state and dynamic simulations are provided in this section. In these results, the terminal voltage of the generator is maintained constant at $380 \mathrm{~V}$. This value of the terminal voltage is one of the merits of the proposed connection, since it is higher than the rated value of the used machine. In steady state, MATLAB program was used to estimate the values of the main and the auxiliary winding capacitors, and the relation between the speed and the values of capacitors under the variation of the load and its power factor will be presented.

\section{Steady-state results}

\section{No-load conditions}

Figure 6a shows the needed capacitances for self-excitation versus the P.U. speed at constant terminal voltage and rated frequency at no-load conditions. It is noticeable that the needed main capacitance increases with the increase of the speed, while the auxiliary capacitance decreases. Figure $6 \mathrm{~b}$ shows the variation of the P.U. speed limits versus the terminal voltage to maintain the operating frequency, under no load, constant at the rated value. It may be noted that the minimum speed is almost constant with the increase of the terminal voltage.

\section{Load conditions}

If the generator has a variable speed prime mover, it is needed to continuously vary the capacitors to deal with the change of the prime mover speed. Under such condition, it is required to examine the speed ranges within which the generator could generate constant load voltage and frequency for different loads. Figure 7a shows the variation of the P.U. speed limits for the resistive loads, while Fig. 7b shows the variation of the P.U. speed limits for inductive loads with a power factor of 0.97 . To maintain constant load voltage and frequency at any speed within the speed ranges, the main and auxiliary capacitors will be determined using the suggested technique. Figure 8 gives the calculated values of the main and auxiliary capacitances versus the operating speed at different loads.
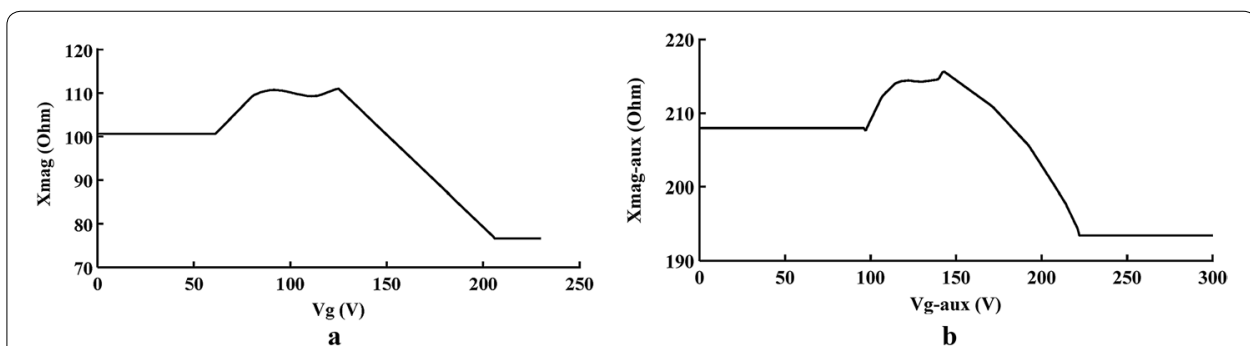

Fig. 5 The magnetization characteristic for a main winding and $\mathbf{b}$ auxiliary winding 

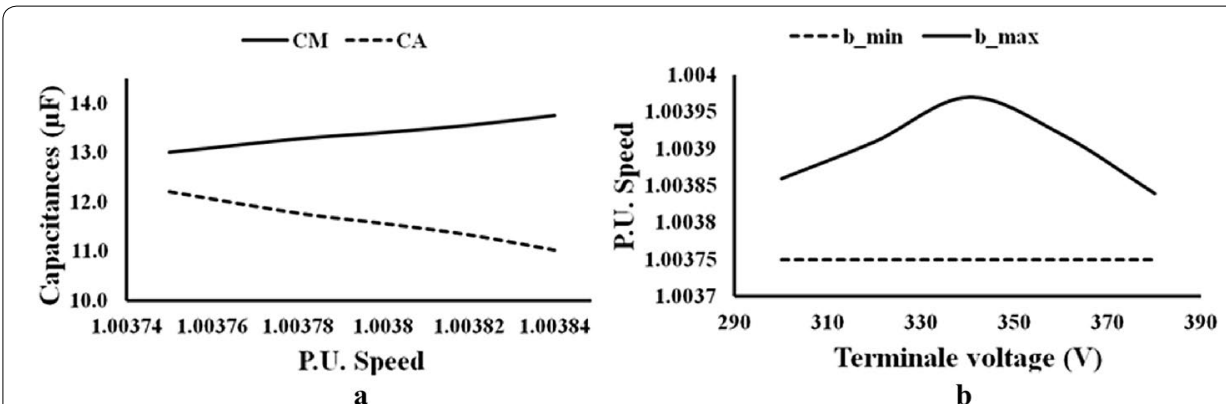

Fig. 6 a Main and auxiliary capacitance versus P.U. speed with constant terminal voltage and rated frequency at no-load conditions, b P.U. speed limits versus no-load terminal voltage at rated frequency
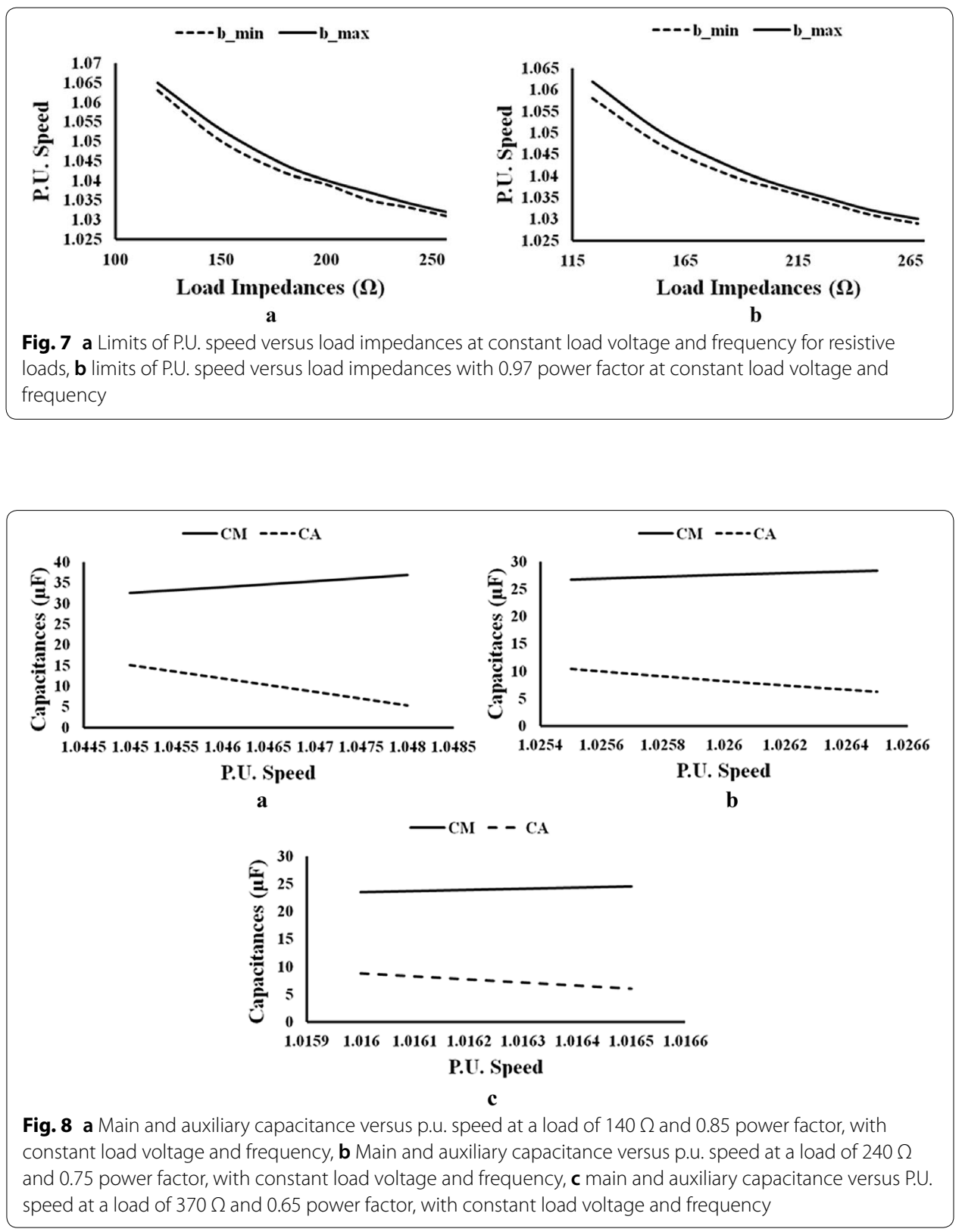


\section{Dynamic results}

For dynamic simulation, MATLAB program was used to show the dynamic response of different voltages and currents building up processes of the studied TWSPSEIG under no-load and load conditions. Figure 9 shows the dynamic response of voltages building up process and the frequency of the terminal voltage of the proposed connection during self-excitation under no-load condition. The generator initially runs at a p.u. speed of $1.0038(1506 \mathrm{rpm})$ with the main capacitance of $13.414 \mu \mathrm{F}$ and an auxiliary capacitance of $11.5 \mu \mathrm{F}$. The corresponding main and the auxiliary currents for building up wave forms closely resemble the voltages waveforms. Figure 10 shows the dynamic response of the studied no-load proposed TWSPSEIG connection subjected to a sudden connection of a resistive load of $120 \Omega$ at time 6 s., with a P.U. speed of $1.063,28.227 \mu \mathrm{F}$ as the main capacitance and $10.5 \mu \mathrm{F}$ as the auxiliary capacitance, and then sudden changing of the P.U. speed to 1.065 at time 7 s., with the main capacitance of $30.712 \mu \mathrm{F}$ and the auxiliary capacitance of $7.05 \mu \mathrm{F}$.

Figure 11 shows the dynamic response of the studied no-load proposed TWSPSEIG connection subjected to a sudden connection of an inductive load of $205 \Omega$ with 0.97 power factor at time $6 \mathrm{~s}$. with a p.u. speed of $1.037,24.266 \mu \mathrm{F}$ as the main capacitance and $9.7 \mu \mathrm{F}$ as the auxiliary capacitance, and then sudden changing of the p.u. speed to 1.038 at time $7 \mathrm{~s}$., with the main capacitance of $25.6 \mu \mathrm{F}$ and auxiliary capacitance of $7.64 \mu \mathrm{F}$.

Figures 10 and 11 illustrate that the load voltage and frequency are almost constant regardless of the values of load impedance, load power factor and operating speed, which is a proof of the validity and accuracy of the proposed technique for calculations of suitable main and auxiliary capacitances.

Table 2 summaries the other cases of dynamic response of the studied no-load TWSPSEIG subjected to a sudden connection of different resistive loads. Table 3

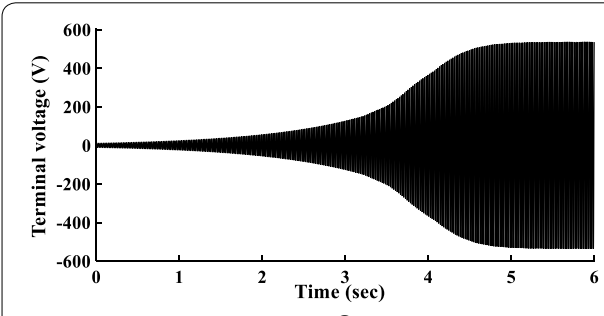

a

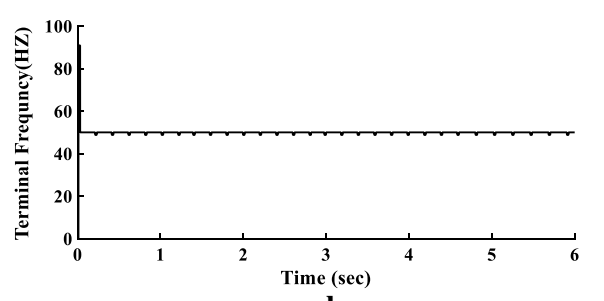

b

Fig. 9 No-load building up process a terminal voltage, b terminal frequency
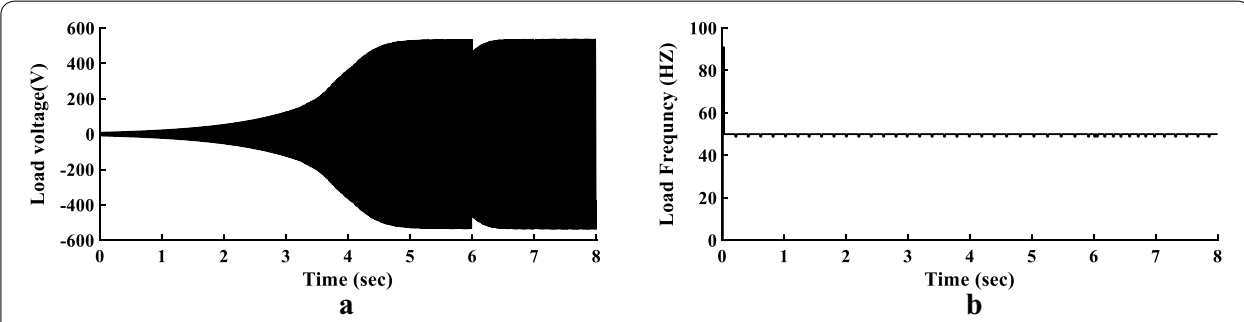

Fig. 10 Dynamic responses of the proposed connection at a resistive load a load voltage, b load frequency 


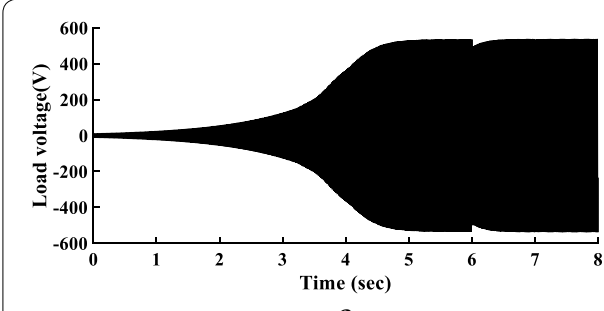

a

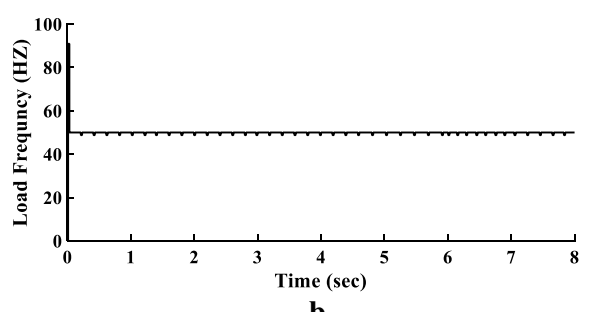

b

Fig. 11 Dynamic responses of the proposed connection at an inductive load $\mathbf{a}$ load voltage, $\mathbf{b}$ load frequency

Table 2 Dynamic responses of the proposed connection of the TWSPSEIG at resistive loads

\begin{tabular}{lllllllll}
\hline $\boldsymbol{R}_{\mathbf{L}}(\boldsymbol{\Omega})$ & p.u. speed & $\boldsymbol{C}_{\mathbf{M}}(\boldsymbol{\mu F})$ & $\boldsymbol{C}_{\mathbf{A}}(\boldsymbol{\mu F})$ & $\boldsymbol{V}_{\mathbf{M}}(\mathbf{V})$ & $\boldsymbol{V}_{\mathbf{A}}(\mathbf{V})$ & $\boldsymbol{I}_{\mathbf{M}}(\mathbf{A})$ & $\boldsymbol{I}_{\mathbf{A}}(\mathbf{A})$ & $\boldsymbol{I}_{\mathbf{L}}(\mathbf{A})$ \\
\hline 120 & 1.064 & 29.494 & 8.76 & 256.28 & 249.6 & 4.75 & 4.87 & 3.17 \\
180 & 1.043 & 21.839 & 10.1 & 238.71 & 263.98 & 3.36 & 3.64 & 2.12 \\
220 & 1.035 & 18.992 & 11.6 & 231.67 & 269.25 & 2.85 & 3.26 & 1.73 \\
260 & 1.031 & 19.473 & 9.1 & 229.59 & 269.41 & 2.75 & 3.11 & 1.46 \\
\hline
\end{tabular}

Table 3 Dynamic responses of the proposed connection of the TWSPSEIG at inductive loads

\begin{tabular}{llllllllll}
\hline $\boldsymbol{Z}_{\mathbf{L}}(\boldsymbol{\Omega})$ & P. F. & p.u. speed & $\boldsymbol{C}_{\mathbf{M}}(\boldsymbol{\mu F})$ & $\boldsymbol{C}_{\mathbf{A}}(\boldsymbol{\mu F})$ & $\boldsymbol{V}_{\mathbf{M}}(\mathbf{V})$ & $\boldsymbol{V}_{\mathbf{A}}(\mathbf{V})$ & $\boldsymbol{I}_{\mathbf{M}}(\mathrm{A})$ & $\boldsymbol{I}_{\mathbf{A}}(\mathrm{A})$ & $\boldsymbol{I}_{\mathbf{L}}(\mathrm{A})$ \\
\hline 125 & 0.97 & 1.059 & 32.629 & 11.2 & 251.214 & 254.643 & 4.345 & 4.524 & 3.04 \\
225 & 0.97 & 1.034 & 23.356 & 9.43 & 231.661 & 268 & 2.887 & 3.229 & 1.688 \\
270 & 0.97 & 1.029 & 21.462 & 9.94 & 227.533 & 270.798 & 2.612 & 3.031 & 1.407 \\
140 & 0.85 & 1.048 & 36.971 & 6.7 & 244.34 & 258.834 & 3.789 & 3.949 & 2.714 \\
240 & 0.75 & 1.026 & 27.638 & 8.4 & 226.386 & 271.686 & 2.553 & 2.941 & 1.583 \\
370 & 0.65 & 1.016 & 23.53 & 8.63 & 218.312 & 276.034 & 2.138 & 2.659 & 1.027 \\
\hline
\end{tabular}

summarizes the other cases of dynamic response of the studied no-load TWSPSEIG subjected to a sudden connection of different inductive loads with different power factors. It is observed that the speed decreases as the load current decreases at constant power factor.

To evaluate the new connection and prove its advantages, the performance of the new connection is compared with that of the traditional connection. In the traditional connection, a TWSPSEIG with an excitation capacitor " $C_{\mathrm{A}}$ " connected across the auxiliary winding and a compensation capacitor " $C_{\mathrm{M}}$ " shunted with the load across the main winding has been studied. The required set values of capacitors (main and auxiliary) have been calculated at different load conditions and operating speed using the same technique. In both connections, the load voltage is maintained constant at $230 \mathrm{~V}$ with the rated frequency. Table 4 shows the comparison of the two connections subjected to a sudden connection of different resistive loads, while Table 5 shows the comparison of two connections subjected to a sudden connection of different inductive loads. 


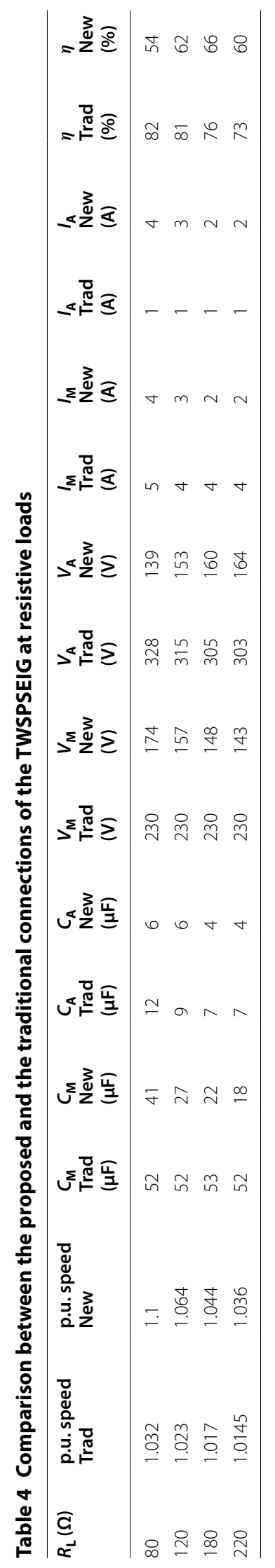




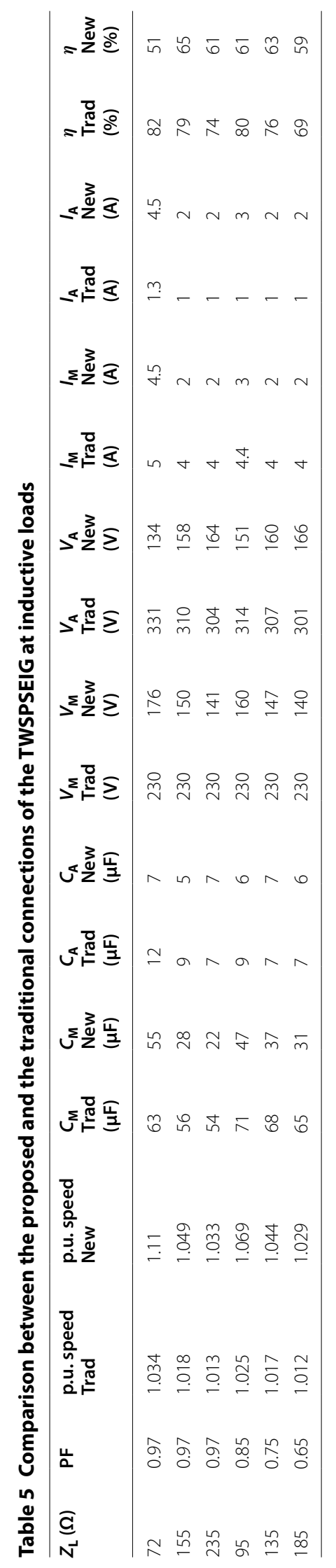


The surveillance of the results in Tables 4 and 5 yields the following significant points:

1. The operating p.u. speed of the proposed connection is higher than that of the traditional connection at the same load.

2. The required capacitors of the proposed connection have always lower values than that of the traditional connection at the same load.

3. The main and auxiliary winding voltages of the proposed connection have always lower values than that of the traditional connection at the same load.

4. The main winding current of the proposed connection has low values when compared with those of the traditional connection at the same load.

5. The auxiliary winding current of the proposed connection has high values, but is still in the safe range at the same load.

6. The efficiency of the proposed connection is lower than that of the traditional connection at the same load, since the operating speed of the proposed connection is higher than that of the traditional connection.

\section{Conclusion}

In this paper, a proposed connection of the two-winding single-phase self-excited induction generator (TWSPSEIG) has been studied in detail and a suitable methodology has been developed. A new technique to determine the required capacitances of the TWSPSEIG with unregulated prime mover is presented to maintain constant load voltage and frequency. It is found that the speed ranges are different according to the values of load impedance and power factor, within which both the load voltage and frequency could be maintained constant. The paper also introduces a new direct and simple method to find the capacitance required for self-excitation at no-load conditions with the variation of the operating speed. The required values of the main and auxiliary capacitors have been designed at different load conditions and operating speed by using a simple iterative technique to maintain the load voltage and frequency constant. To verify the steadystate results, the paper introduces a dynamic model of the proposed connection of the TWSPSEIG incorporating various no-load, load conditions and its nonlinearity behavior. The dynamic behavior of the TWSPSEIG at different operating conditions proves the capabilities of the proposed configuration and calculation method to maintain both the load voltage and frequency constant. To evaluate the proposed connection and prove its advantages, the performance of the proposed connection is compared with that of the traditional connection. The comparison proved that the proposed connection has many advantages when compared with the traditional connection at the same load, such as low values of the required capacitors, low values of the main and auxiliary winding voltages and low values of the main winding current, while the main disadvantage of the proposed connection is its low efficiency because it has high operating speed. 


\section{Acknowledgements}

Not applicable.

\section{Authors' contributions}

$\mathrm{HH}$ proposed the research point and contributed in the survey and data collection, in deriving the mathematical analytical model, building the steady-state models and dynamic models for the proposed method and the method found in literature, simulation and derivation of results, analyzing the results, and writing the manuscript and the technical review. HS contributed in the survey and data collection, in deriving the mathematical analytical model, building the steadystate models and dynamic models for the proposed method and the method found in literature, running the simulation and derivation of results, analyzing the results and writing the manuscript and the technical review. AS contributed in deriving the mathematical analytical model, building the steady-state models and dynamic models for the proposed method and the method found in literature, running the simulation and derivation of results, analyzing the results, writing the manuscript, editorial and grammatical review, technical review, submission of paper and applying the received review comments. ME contributed in the editorial and grammatical review and the technical review. All authors read and approved the manuscript.

\section{Funding}

Not applicable, no funding was received.

\section{Availability of data and materials}

The data for the machine used was obtained from Ref:. [22].

\section{Competing interests}

The authors declare that they have no competing interests.

\section{Author details}

${ }^{1}$ Electrical Power Engineering Department, Faculty of Engineering, Cairo University, Giza 12613, Egypt. ${ }^{2}$ Electrical Engineering Department, Faculty of Engineering, Fayoum University, Fayoum 63514, Egypt.

Received: 5 September 2019 Accepted: 15 October 2019

Published online: 27 November 2019

\section{References}

1. Mahley S, Jain SK (2016) Investigations on single-phase two winding self-excited induction generator for optimal operation with different capacitor topologies. In: 7th international conference on power electronics (IICPE), Patiala, India, pp 1-6

2. Mahley S, Jain SK (2016) Optimal operation of single-winding self-excited induction generator for single-phase power generation. In: 7th international conference on power electronics (IICPE), Patiala, India, pp 1-5

3. Kallla UK, Singh B, Jain D (2015) A study of experimental investigations on two winding single-phase self-excited induction generators. In: IEEE IAS joint industrial and commercial power systems/petroleum and chemical industry conference (ICPSPCIC), Hyderabad, India, pp 45-51

4. Khan MF, Khan MR (2014) Voltage control of single-phase two winding self-excited induction generator for isolated loads. In: International conference on advances in energy conversion technologies (ICAECT), Manipal, India, pp 209-214

5. Singh B, Shilpakar LB, Murthy SS, Tiwari AK (2000) Improved steady state and transient performance with optimum excitation of single-phase self-excited induction generator. Electr Mach Power Syst 28:591-604

6. Anagreh YN (2006) Matlab-based steady-state analysis of single-phase self-excited induction generator. Int J Model Simul 26(3):271-275

7. Velusami S, Singaravelu S (2007) Steady state modeling and fuzzy logic based analysis of wind driven single phase induction generators. Renew Energy 32:2386-2406

8. Khan MF, Khan MR, labal A (2013) Performance comparison of single winding and double winding self-excited induction generators. In: IEEE conference on clean energy and technology (CEAT), Langkawi, Malaysia, pp 202-207

9. Kalla UK, Singh B, Murthy SS (2015) Enhanced power generation from two-winding single-phase SEIG using LMDTbased decoupled voltage and frequency control. IEEE Trans Ind Electron 62(11):6934-6943

10. Senthilkumar M (2010) Optimal capacitor for maximum output power tracking of self excited induction generator using fuzzy logic approach. Int J Comput Sci Eng 02(05):1758-1762

11. Kalla UK, Singh B, Murthy SS (2016) Implementation of voltage controller of single-phase self-excited induction generator. Electr Power Compon Syst 44:1276-1290

12. Kalla UK, Singh B, Murthy SS (2016) Intelligent neural network-based controller for single-phase wind energy conversion system using two winding self-excited induction generator. IEEE Trans Ind Inf 12(6):1986-1997

13. Kalla UK, Singh B, Murthy SS (2016) Modified electronic load controller for constant frequency operation with voltage regulation of small hydro-driven single-phase SEIG. IEEE Trans Ind Appl 52(4):2789-2800

14. Ünal S, Özdemir M, Sünter S (2004) Voltage and frequency control of a single-phase self-excited asynchronous generator. In: International aegean conference on electrical machines and power electronics (ACEMP), Istanbul, Turkey, pp 509-514

15. Muljanto WP, Dalimi R (2017) Secondary voltage control of single phase induction generator operated in small scale picohydro power plant at off-grid area. In: 15th international conference on quality in research (QiR): international symposium on electrical and computer engineering, Nusa Dua, Indonesia, pp 303-308 
16. Liyanage D, Rajakaruna S (2015) An improved dynamic model for a single-phase generator based on three-phase cage rotor induction machine. In: The 11th IEEE international conference on power electronics and drives systems (PEDS 2015), Sydney, Australia, pp 934-939

17. Wu XZ, Zhang Y (2015) Steady-state analysis of islanded three-phase induction generator in single-phase operation with combined equivalent circuit. In: Proceedings of 2015 IEEE international conference on applied superconductivity and electromagnetic devices, Shanghai, China, pp 118-119

18. Ion CP, Marinescu C (2013) Three-phase induction generators for single-phase power generation: an overview. Renew Sustain Energy Rev 22:73-80

19. Chatterjee A, Roy K, Chatterjee D, Ganguli AK (2014) Development of low cost single phase self excited wind generator using three phase machine. In: The 2014 international conference on control, instrumentation, energy \& communication (CIEC). Calcutta, India, pp 316-320

20. Kim B, Pietrzak-David M, Maussion P, Bun L (2017) Novel structure of single-phase generator from three-phase induction machine: modeling and simulation. In: 43rd annual conference of the IEEE industrial electronics society, IECON 2017, Beijing, China, pp 7653-7659

21. Gao S, Bhuvaneswari G, Murthy SS, Kalla U (2014) Efficient voltage regulation scheme for three-phase self-excited induction generator feeding single-phase load in remote locations. IET Renew Power Gener 8(2):100-108

22. Mahato SN, Singh SP, Sharma MP (2013) Dynamic behavior of a single-phase self-excited induction generator using a three phase machine feeding single-phase dynamic load. Electr Power Energy Syst 47:1-12

\section{Publisher's Note}

Springer Nature remains neutral with regard to jurisdictional claims in published maps and institutional affiliations.

\section{Submit your manuscript to a SpringerOpen ${ }^{\odot}$ journal and benefit from:}

- Convenient online submission

- Rigorous peer review

Open access: articles freely available online

- High visibility within the field

Retaining the copyright to your article

Submit your next manuscript at $\mathbf{s p r i n g e r o p e n . c o m ~}$ 